\title{
Factors associated with low male partners' involvement in maternal and child health services in Suba sub county, Western Kenya
}

\author{
Noel Otieno Odhiambo ${ }^{1}$, Harrison Atieli ${ }^{2}$ and Louisa Ndunyu ${ }^{2}$ \\ ${ }^{I}$ African Medical and Research Foundation \\ ${ }^{2}$ Department of Public Health, School of Public Health and Community Development, Maseno University, \\ Kenya.
}

\begin{abstract}
Objective: Male involvement (MI) in maternal and child health (MCH) services such as pre-conception care, antenatal care (ANC), prevention of mother-to-child transmission (PMTCT) of HIV, skilled delivery is an integral intervention that improves MCH outcomes. Suba sub County in western Kenya has the highest prevalence of HIV in Kenya. Moreover, data is skewed on men's knowledge and perceptions regarding their involvement in $\mathrm{MCH}$ services.

Methods: This mixed method cross-sectional study, collected data using questionnaire among 354 male participants, and conducted 4 focus group discussions (FGDs) and 6 key informant interviews (KIIs). STATA version 11 was used for quantitative data analysis. The thematic content analysis was used to analyze qualitative data.

Results: The majority of the participants $(52.3 \%)$ were aged $>30$ years, $44.9 \%$ had primary level of education and $63.1 \%$ engaged in fishing activities. About $54.5 \%$ of the participants were not aware of the Ministry of Health's effort to enhance men's attendance to MCH clinics, while men's age, various cultural taboos and provider's attitude were perceived as influencing $\mathrm{MI}$ in $\mathrm{MCH}$ services. Overall $16.3 \%$ of the participants were involved in $\mathrm{MCH}$ services. Health worker provider's attitude towards men (OR $0.5,95 \% \mathrm{Cl} 0.3$ to 0.8 ), men's preferred time of attending $\mathrm{MCH}$ clinic (OR 6.7, $95 \% \mathrm{Cl} 1.1-43.5$ ), the frequency of men accompanying spouse to $\mathrm{MCH}$ clinic (OR $0.1,95 \% \mathrm{Cl} 0.04-0.3$ ), duration taken to reach $\mathrm{MCH}$ clinic (OR 5.6, $95 \% \mathrm{Cl} 1.3-24.6$ ), use of family planning methods (OR 0.36, 95\% Cl 0.18-0.72) and awareness about the methods used to reduce HIV mother to child transmission (MTCT) (OR 35, 95\% Cl 0.19-0.65) were independently associated with men's attendance of the $\mathrm{MCH}$ clinics.

Conclusion: Significantly there was low male involvement in $\mathrm{MCH}$ services $(16.3 \%$ compared to the $>30 \%$ targets by Kenya PMTCT guidelines, 2012) in this high HIV prevalent region. Enhanced dissemination and awareness creation on the importance of MI in MCH services could improve male involvement

Key words: Male Involvement, Maternal and Child Health Services, Knowledge, Perceptions and Correlates, Suba sub county western Kenya

DOI: $10.7176 / \mathrm{JHMN} / 60-15$

Publication date:March $31^{\text {st }} 2019$

\section{BACKGROUND}

Maternal and child mortality remains a significant public health concern globally, and in sub-Saharan Africa, where $87 \%$ of the global rates occur, the Maternal Mortality Ratio (MMR) was 546 deaths per 100,000 live births (WHO, 2016). In Kenya, the national MMR was 362 maternal deaths per 100,000 live births and 583 per 100,000 live births in Homa-Bay County, the current study site (KNBS, 2014). HIV infection is one of the major health indicators associated with maternal and child health outcome (WHO, 2016). Kenya is ranked among the countries with high HIV burden in Africa with an estimated 1.5 million people living with HIV and a national prevalence of $5.9 \%$ (KNBS, 2014; UNAIDS, 2015). Homa-Bay County ranks among top 5 counties with the highest HIV prevalence in Kenya with a $26 \%$ infection rates, 4.5 times higher than the national HIV prevalence, its MTCT rate is $16.8 \%$ twice the national average (NACC, 2016).

Male Involvement (MI) in Maternal and Child Health (MCH) services is defined as various ways in which men relate to reproductive health activities and problems, men attendance to $\mathrm{MCH}$ clinics and reproductive health responsibilities (DeCock, 2012). Male involvement is a crucial component to optimize MCH services. Until the 1990 's, interventions on maternal health targeted only women, promoting women's visits to health facilities for MCH services (Nwakwuo \& Oshonwoh, 2013). The recognition that male involvement is critical for improving maternal and child health services, has led to increased advocacy for male involvement in MCH (Kululanga et al., 2011). This recognition shaped the recommendations made at the 1994 International Conference on Population 
and Development, which urged interventions that take to account men's shared responsibility in improving $\mathrm{MCH}$. Since the increased focus on male involvement, the role of men in maternal health has been seen as the missing link in improving maternal and child health indicators (Kululanga et al., 2011). Studies on male participation in MCH services showed significant positive impact on the household (Gungor \& Beji, 2007; Alio et al., 2010) including better decision-making on health for the couple and children, increased disclosure of HIV status with increased likelihood to adopt low risk behaviors, better adoption of HIV of prevention practices including PMTCT and increased compliance to family planning and infant nutrition (Ditekemena et al., 2012; Comrie-Thomson et al., 2015; Brubaker et al., 2016). Some studies have found that health interventions that target and involve men are strongly associated with enhanced and better birth outcomes and increased use of skilled maternal healthcare services (Nanjala \& Wamalwa, 2012; Nkuoh et al., 2010). This includes safer birth practices, family planning, HIV prevention, birth preparedness, emergency obstetric access, emotional support and partner communication (Ampt et al., 2015; Yargawa \& Leonardi-Bee, 2015).

Although male involvement in reproductive health issues has gained more visibility, gender beliefs still define roles and influence how maternal health issues are approached in many parts of the developing world (Yargawa \& Leonardi-Bee, 2015). Further, MI in MCH services still remains a challenge because of the poor or lack of awareness and perceived cultural practices and taboos (Kwambai et al., 2013; August et al., 2015; Yargawa \& Leonardi-Bee, 2015). This study sought to assess men's involvement in MCH services, their knowledge, perceptions and correlates for their involvement Suba sub county in Homabay County hardest hit counties with highest prevalence of HIV in western Kenya.

\section{METHODOLOGY}

\section{Study design and sample collection}

This mixed method cross-sectional study enrolled consenting men aged ( $\geq 18$ years), with least a child aged below 5 years old or a pregnant wife (s) and natives of Suba. For structured interviews, using the Lemeshow et al. (1990) formula for estimating the population proportion with specified relative precision and setting $\propto$ at 0.05 , and a $30 \%$ prevalence of male involvement in MCH (PMTCT guideline, 2016), a total of 354 men were recruited to achieve 0.95 power. These men were chosen from Suba, Nyamarandi and Sumba west community units respectively with already assigned community health volunteers and linked to Suba sub County Hospital.

\section{Data Collection}

The structured interviews were conducted by Community Health Volunteers who identified the men to be interviewed from their households. The participants were screened for eligibility, consented then interviewed, in a private and confidential place.

A total of 4 FGD were conducted to explore further the levels of male involvement, knowledge and perception and associated factors in this region. Twelve (12) adult men were randomly selected from the three (3) Community Units, consented and enrolled in two (2) FGDs composed of six men each. A similar process was applied for the two (2) FGDs composed of six (6) female adults each. The FGDs were conducted at an agreed time, date and location. Using an FGD guide, an experienced moderator, assisted by a note-taker, conducted these discussions in the Dholuo language. The FGDs lasted approximately 45 minutes and were recorded on tape.

Interviews with six (6) key informant including, health professionals, religious and tribal leaders, and wellregarded women in the community are experienced in $\mathrm{MCH}$ were conducted to confirm and clarify any pending or new issues captured in the questionnaires and FGDs. Key informant interviews have been shown to provide a valuable foundation for a broader understanding of contextual matters relevant to the issues being explored (Bernard, 1994). The key informants were selected based on their position of leadership, either formal or informal, in the community and their ability and willingness to discuss issues surrounding MI. In addition, key informants were those observant, articulate and available for multiple interviews of varying duration on an assortment of topics related to the study.

\section{Ethical considerations}

The research protocol was presented for scientific and ethical approvals by the Maseno University School of Graduate Studies (SGS) and the Ethical Review Committee (MSU/DRPI/MUERC/00249/15) prior to commencement of field activities. Written informed consent was obtained from each participant. Confidentiality 
was maintained by assigning all participants with a unique identification number and all paper research records stored in a locked cabinet stationed in a secured restricted room.

\section{Statistical analysis}

Quantitative data was analyzed using STATA version 13.1 (Stata Corp LP, College Station, TX, USA). Descriptive statistics frequency (\%) and mean was used to express quantitative data. The overall MI in MCH services was determined for all participants. In bivariate analyses, odds ratios (OR) and 95\% confidence intervals (CI) for the association between MI in MCH services and socio-demographic, household demographic, knowledge and perception characteristics were calculated using Poisson regression. In multivariate analyses, a manual backward elimination approach was used to reach the most parsimonious model including factors that were associated with $\mathrm{MI}$ in $\mathrm{MCH}$ services among men in Suba sub County at the significance level of $\mathrm{P} \leq 0.05$.

The qualitative data (FGD and KII) were subjected to a thematic content analysis. This approach entails the categorization of recurrent data collected under thematic areas (Green \& Thorogood, 2010). The analysis was done using Nvivo 8

\section{RESULTS}

\section{Population characteristic}

Table 1 summarizes the characteristics of the study population. Analyzable data were available for 352 out of the $354(99.4 \%)$ response rate. The majority of the participants $52.3 \%$ were aged $\geq 30$ years, $44.9 \%$ had primary education, $49.4 \%$ were of Suba ethnic community, $85 \%$ were Christian. Further, the majority of participants when combined engaged in fishing activities including; 79 (22.4\%) were fish traders, 59 (16.8\%) were fishermen and $11(3.1 \%)$ boat owners, $92.6 \%$ were married.

\section{Men's knowledge on MCH services}

The study showed that $54.5 \%$ were not knowledgeable on the $\mathrm{MOH}$ effort to enhance men attendance to $\mathrm{MCH}$ clinics, $42.9 \%$ accompanied their spouses to clinic more than once and $45.2 \%$ stated four times as the recommended number of visits of ANC attendance. Concerning the services offered at ANC, the majority $42.6 \%$ stated HIV testing and counseling as well as immunization as the main services offered at the ANC clinic. Only $34.4 \%$ of these men were knowledgeable of the benefits of ANC clinics with $18.8 \%$ recognizing issuance of free mosquito while $15.6 \%$ stated that mothers are given mosquito nets, are tested and given appropriate drugs for prophylaxis as well as condoms are offered ate the ANC clinics. The majority $67.6 \%$ of men accompanied their spouses for HIV counselling and testing with spouse while $70.5 \%$ were knowledgeable on the methods to reducing HIV mother to child transmission. When probed about methods aimed at reducing PMTCT, 15.9\% stated exclusive breast feeding while $22.7 \%$ stated a combination of methods exclusive breast feeding and uptake of ARV for mother and child. Different single or combination of responses concerning benefits of breastfeeding were reported; $24.4 \%$ stated that breast milk leads to healthier baby who are resistant to disease and ending up having strong bones while $20.5 \%$ stated combination of breast milk benefits including healthier baby resistant to disease, having strong bones and with fewer weight problems.

These men attributes concerning men's knowledge on MCH were confirmed both from FGD and KII. Men in this region were generally reported as lacking appropriate knowledge affecting the uptake of $\mathrm{MCH}$ services. One FGD 2 a male participant stated "I think most of them are ignorant on MCH services stating that it is not them get pregnant but the woman. So even if the woman tells him to accompany her to the clinic he doesn't see the need. Because it is the mother who is going to be tested, and it's the woman who will feel the pain and done for all those activities in the MCH. They don't have any knowledge about being involved in the MCH'.

\section{Men's perception on MCH services}

Some of the men's perceptions of attributes affecting their involvement in $\mathrm{MCH}$ services included $52.8 \%$ reporting age as a key contributor to men's attendance of ANC clinic while 47.2\% reported service waiting time was key on their $\mathrm{MCH}$ service involvement. Cultural and community taboos were also perceived to influence men involvement in $\mathrm{MCH}$ services. These cultural and taboos included, men household headship role and that child birth and pregnancies are women's affair; $19.9 \%$ of the participants stated that men are the head of the house and should spend time looking for food for family while $14.2 \%$ believed that men should not be involved in women's affair. The attitude of health provider was also sighted as key determinant in uptake of MCH by men. About $63.4 \%$ of the responded stated that provider's attitude influences male involvement in maternal and child services. Concerning income slightly over half of them $58.5 \%$ stated that income influenced male participation in maternal 
and child services. When asked about what clinical operation hours they would prefer for men to participate in maternal and child services, majority $79.5 \%$ preferred 8 to 12 am while only $2.6 \%$ had no time preferences.

Table 1: Baseline characteristics of study population

\begin{tabular}{|c|c|c|c|c|c|c|c|}
\hline \multirow{3}{*}{ Variable } & & \multicolumn{5}{|c|}{ Men's attendance in MCH clinic } & \multirow{3}{*}{$\mathbf{P}$} \\
\hline & \multicolumn{2}{|c|}{ Overall $(N=354)$} & \multicolumn{2}{|c|}{ Yes $(n=57)$} & \multicolumn{2}{|c|}{ No $(n=295)$} & \\
\hline & No & $\%$ & No & $\%$ & No & $\%$ & \\
\hline \multicolumn{8}{|l|}{ Age } \\
\hline 18 Years & 9 & 2.6 & 2 & 22.2 & 7 & 77.8 & \\
\hline 18-30 Years & 159 & 45.2 & 28 & 17.6 & 131 & 82.4 & 0.674 \\
\hline$>30$ years & 184 & 52.3 & 27 & 14.7 & 157 & 85.3 & \\
\hline \multicolumn{8}{|l|}{ Education Level } \\
\hline Primary & 158 & 44.9 & 22 & 13.9 & 136 & 86.1 & \\
\hline Secondary & 130 & 36.9 & 24 & 18.5 & 106 & 81.5 & 0.671 \\
\hline College/University & 56 & 15.9 & 9 & 16.1 & 47 & 83.9 & \\
\hline None-Formal & 8 & 2.3 & 2 & 25.0 & 6 & 75.0 & \\
\hline \multicolumn{8}{|l|}{ Tribe } \\
\hline Luo & 136 & 38.6 & 19 & 14.0 & 117 & 86.0 & \\
\hline Suba & 174 & 49.4 & 29 & 16.7 & 145 & 83.3 & \\
\hline Kisii & 17 & 4.8 & 3 & 17.6 & 14 & 82.4 & 0.864 \\
\hline Kuria & 3 & 0.9 & 1 & 33.3 & 2 & 66.7 & \\
\hline Decline & 9 & 2.6 & 2 & 22.2 & 7 & 77.8 & \\
\hline Others & 13 & 3.7 & 3 & 23.1 & 10 & 76.9 & \\
\hline \multicolumn{8}{|l|}{ Religion } \\
\hline Muslim & 8 & 2.3 & 1 & 12.5 & 7 & 87.5 & \\
\hline Protestant & 167 & 47.4 & 33 & 19.8 & 134 & 80.2 & 0.33 \\
\hline Catholic & 134 & 38.1 & 16 & 11.9 & 118 & 88.1 & \\
\hline Other & 43 & 12.2 & 7 & 16.3 & 36 & 83.7 & \\
\hline \multicolumn{8}{|l|}{ Occupation } \\
\hline Fisherman & 59 & 16.8 & 9 & 15.3 & 50 & 84.7 & \\
\hline Boat Owner & 11 & 3.1 & 2 & 18.2 & 9 & 81.8 & 0.728 \\
\hline Fish Trader & 79 & 22.4 & 12 & 18.2 & 67 & 84.8 & \\
\hline Farmer & 105 & 29.8 & 14 & 13.3 & 91 & 86.7 & \\
\hline Others & 98 & 27.8 & 20 & 20.4 & 78 & 79.6 & \\
\hline \multicolumn{8}{|l|}{ Marital status } \\
\hline Single & 18 & 5.1 & 3 & 16.7 & 15 & 83.3 & \\
\hline Married & 326 & 92.6 & 52 & 16 & 274 & 84 & 0.789 \\
\hline Others & 8 & 2.3 & 2 & 25 & 6 & 75 & \\
\hline \multicolumn{8}{|l|}{ Number of Wives } \\
\hline One & 275 & 78.1 & 44 & 16 & 231 & 84 & \\
\hline Two & 53 & 15.1 & 10 & 18.9 & 43 & 81.1 & 0.852 \\
\hline Three & 5 & 1.4 & 1 & 20 & 4 & 80 & \\
\hline Others & 19 & 5.4 & 2 & 10.5 & 17 & 89.5 & \\
\hline \multicolumn{8}{|l|}{ Duration in Marriage } \\
\hline$<5$ Years & 71 & 20.2 & 15 & 4.8 & 56 & 78.9 & \\
\hline$>5$ years & 183 & 52 & 32 & 17.5 & 151 & 82.5 & 0.197 \\
\hline$>10$ Years & 77 & 21.9 & 9 & 11.7 & 68 & 88.3 & \\
\hline Not applicable & 21 & 6 & 1 & 4.8 & 20 & 95.2 & \\
\hline
\end{tabular}

Men's attendance in MCH clinic

The attendance of men in the $\mathrm{MCH}$ clinic was measured by asking men if they had ever accompanied their spouse (s) to PMTCT or ANC or MCH clinic. Only $58(16.3 \%)$ men had ever accompanied their spouse(s) to these various clinics far below the average expectations $(\geq 30 \%)$ by the ministry of health. 


\section{Factors associated with men's attendance of MCH clinic}

\section{MCH Knowledge as a factor}

Table 2 summarizes Men's Knowledge factors associated with attendance of MCH clinic. In bivariate analysis, male participants who were more likely to accompany their spouses to $\mathrm{MCH}$ clinics were knowledgeable of the $\mathrm{MOH}$ effort to enhance men attendance to $\mathrm{MCH}$ clinics $(\mathrm{OR} 10,95 \% \mathrm{Cl} 3.3-30.5$, took 30 minutes $(\mathrm{OR} 5.6,95 \% \mathrm{Cl}$ 1.3-24.6), 30 to 60 minutes ( $\mathrm{OR} 7.5,95 \% \mathrm{Cl} 1.7-32.1)$ and more than 60 minutes (OR 7.9, 95\% $\mathrm{Cl} 1.8-33.7)$ to attend any $\mathrm{MCH}$, stated thrice $(\mathrm{OR} 3.3,95 \% \mathrm{Cl} 1.3-9.1)$ and fourth $(\mathrm{OR} 3.4,95 \% \mathrm{Cl} 1.4-8.1)$ as the recommended number of time for the ANC attendance. Further, participants who stated HIV counseling and Testing and Immunization (OR 8.8, 95\% Cl 1.2-64.5) and HIV testing, Immunization and Malaria prophylaxis $(\mathrm{OR} 8.3,95 \% \mathrm{Cl}$ 1.1-64.5) as some of the services obtained from the ANC clinics as well as participants who had ever gone for HIV counselling and testing with spouse $(\mathrm{OR} 1.9,95 \% \mathrm{Cl} 1.6-3.9)$ were more likely to attend $\mathrm{MCH}$ clinic together with their wives. On the other hand, male participants who less likely to accompany their spouse to any MCH clinic if; they had previously accompanied their spouse (s) only once for $\mathrm{MCH}(\mathrm{OR} 0.1,95 \% \mathrm{Cl} 0.04-0.3)$, men knew ways of reducing MTCT of HIV (OR $0.23,95 \% \mathrm{Cl} 0.14-0.39)$, men who did not use family planning (OR $0.24,95 \% \mathrm{Cl}$ $0.13-0.43$ ), men who partners delivered their last child at home (OR $0.31,95 \% \mathrm{Cl} 0.16-0.16$ ) or at traditional birth attendant (OR 0.22, 95\% Cl 0.11-0.44).

In multivariate analysis, awareness of $\mathrm{MOH}$ effort for men to accompany their spouse (s) to $\mathrm{MCH}$ clinic, number of time accompanied spouse to $\mathrm{MCH}$ clinic, time taken to accompany spouse for the $\mathrm{MCH}$ clinic, use of family planning methods, place of last child delivery and awareness about the methods used to reduce HIV mother to child transmission were independently associated with men's attendance of the MCH clinics.

\section{MCH perception as a factor}

As shown in Table 3; in bivariate analysis, male participants were more likely to accompany their spouses for MCH services if: they had no specific preferred time for clinic operation hour in maternal and child services (OR7.6, 95\% 1 Cl 1.4-40.3). On the other hand, participants were less likely to accompany their spouses for $\mathrm{MCH}$ clinic if they did not agree that the provider's attitude influences male involvement (OR $0.5,95 \% \mathrm{Cl} 0.3-0.8)$. In multivariate analysis, provider's attitude and preferred time of clinic operation hour for $\mathrm{MCH}$ services were independently associated with men's attendance of the MCH clinics. 
Table 2: Factors related to Men's knowledge associated with attendance to MCH clinics

\begin{tabular}{|c|c|c|c|c|c|c|}
\hline \multirow{3}{*}{ Variable } & \multicolumn{5}{|c|}{ Men's attendance in MCH } & \multirow{3}{*}{$\begin{array}{l}\text { Multivariate } \\
\text { aOR }(95 \% \mathrm{CI})\end{array}$} \\
\hline & \multicolumn{2}{|c|}{ Overall population } & \multicolumn{2}{|c|}{ clinic } & \multirow{2}{*}{$\begin{array}{c}\text { Bivariate } \\
\text { uOR }(95 \% \mathrm{CI})\end{array}$} & \\
\hline & No & $\%$ & No & $\%$ & & \\
\hline \multicolumn{7}{|l|}{$\begin{array}{c}\text { Aware of MOH effort for MCH } \\
\text { attendance }\end{array}$} \\
\hline Yes & 160 & 45.5 & 36 & 22.5 & $10(3.3-30.5)$ & $9.8(3.2-30.3)$ \\
\hline No & 192 & 54.5 & 21 & 10.9 & Reference & Reference \\
\hline \multicolumn{7}{|l|}{ Number of time accompanied spouse for } \\
\hline \multicolumn{7}{|l|}{ МСH } \\
\hline 1 & 52 & 14.8 & 14 & 26.9 & $0.1(0.04-0.3)$ & $0.1(0.04-0.3)$ \\
\hline$>1$ & 151 & 42.9 & 39 & 25.8 & $1.1(0.5-1.9)$ & $1.1(0.5-1.9)$ \\
\hline None & 149 & 42.3 & 4 & 2.7 & Reference & Reference \\
\hline \multicolumn{7}{|l|}{ Time taken to accompany spouse for } \\
\hline \multicolumn{7}{|l|}{ МСН } \\
\hline $30 \mathrm{Min}$ & 90 & 25.6 & 14 & 15.6 & $5.6(1.3-24.6)$ & $5.6(1.3-24.6)$ \\
\hline $30-60$ Min & 86 & 24.4 & 18 & 20.9 & $7.5(1.7-32.1)$ & $7.5(1.7-32.1)$ \\
\hline$>60 \mathrm{Min}$ & 104 & 29.5 & 23 & 22.1 & $7.9(1.8-33.7)$ & $7.9(1.8-33.7)$ \\
\hline Not stated & 72 & 20.5 & 2 & 2.8 & Reference & Reference \\
\hline \multicolumn{7}{|l|}{ Recommended attendance } \\
\hline Twice & 37 & 10.5 & 6 & 16.2 & $2.6(0.9-8.2)$ & \\
\hline Three Times & 58 & 16.5 & 12 & 20.7 & $3.3(1.3-9.1)$ & NS \\
\hline Four Times & 159 & 45.2 & 33 & 20.80 & $3.4(1.4-8.1)$ & \\
\hline Not stated & 98 & 27.8 & 6 & 6.1 & Reference & \\
\hline \multicolumn{7}{|l|}{ Services offered at ANC clinic } \\
\hline HIV counseling and Testing & 19 & 5.4 & 2 & 10.5 & $4.6(0.4-51.1)$ & \\
\hline $\begin{array}{l}\text { HIV counseling and Testing and } \\
\text { Immunization }\end{array}$ & 150 & 42.6 & 30 & 20 & $8.8(1.2-64.5)$ & \\
\hline $\begin{array}{l}\text { HIV testing, Immunization and Malaria } \\
\text { prophylaxis }\end{array}$ & 63 & 17.9 & 12 & 19 & $8.3(1.1-64.5)$ & NS \\
\hline \multicolumn{7}{|l|}{ HIV counseling and Testing, Immunization, } \\
\hline $\begin{array}{l}\text { Malaria prophylaxis and Other medical } \\
\text { services }\end{array}$ & 38 & 10.8 & 8 & 21.1 & $7.8(0.9-64.2)$ & \\
\hline Other combined different ANC services & 38 & 10.8 & 4 & 10.5 & $5.9(0.7-50.9)$ & \\
\hline Not stated & 44 & 12.5 & 1 & 2.3 & Reference & \\
\hline \multicolumn{7}{|l|}{ Gone for HIV counselling and testing } \\
\hline \multicolumn{7}{|l|}{ with spouse } \\
\hline Yes & 238 & 67.6 & 45 & 18.9 & $1.9(1.6-3.9)$ & NS \\
\hline No & 114 & 32.4 & 12 & 10.5 & Reference & \\
\hline \multicolumn{7}{|l|}{ Aware of methods to reducing HIV } \\
\hline \multicolumn{7}{|l|}{ mother to child transmission } \\
\hline Yes & 248 & 70.5 & 46 & 18.5 & $0.23(0.14-0.39)$ & $0.35(0.19-0.65)$ \\
\hline No & 104 & 29.5 & 11 & 12.5 & Reference & Reference \\
\hline \multicolumn{7}{|l|}{ Using Family planning methods with } \\
\hline Yes & 278 & 79.0 & 47 & 16.9 & $0.24(0.13-0.43)$ & $0.36(0.18-0.72)$ \\
\hline No & 74 & 21.0 & 10 & 13.5 & Reference & Reference \\
\hline Family planning methods currently usin & & & & & & \\
\hline with spouse & & & & & & \\
\hline IUD & 3 & 0.9 & 0 & 0 & $0.8(0.9-6.5)$ & \\
\hline Implant & 55 & 15.6 & 12 & 21.8 & $1.5(0.7-3.6)$ & \\
\hline Pills & 40 & 11.4 & 3 & 7.5 & $1.1(0.4-2.7)$ & NS \\
\hline Injectable & 72 & 20.5 & 13 & 18.1 & $1.1(0.5-2.5)$ & \\
\hline Natural method & 10 & 2.8 & 3 & 30 & $0.7(0.08-5.2)$ & \\
\hline Female and male condoms & 105 & 29.8 & 19 & 18.1 & $0.9(0.4-2.1)$ & \\
\hline Not stated & 67 & 19.0 & 7 & 10.4 & Reference & \\
\hline Place of delivery of last child & & & & & & \\
\hline Home & 42 & 11.9 & 4 & 9.5 & $0.31(0.16-0.61)$ & $0.52(0.24-1.13)$ \\
\hline TBA & 68 & 19.3 & 5 & 7.4 & $0.22(0.11-0.44)$ & $0.29(0.13-0.65)$ \\
\hline Hospital & 242 & 68.7 & 48 & 19.8 & Reference & Reference \\
\hline
\end{tabular}

No - Number; \% - Percentage; OR - Odds ratio; CI - confidence interval; NS - Not significant; u - Unadjusted odds ratio; a - adjusted OR 
Table 3: Factors related to Men's perception associated with attendance to MCH clinics

\begin{tabular}{|c|c|c|c|c|c|c|c|c|}
\hline \multirow[t]{2}{*}{ Variable } & \multicolumn{2}{|c|}{ Overall population } & \multicolumn{2}{|c|}{$\begin{array}{l}\text { Men's attendance in } \\
\text { MCH clinic }\end{array}$} & \multirow[t]{2}{*}{$P$ - value } & \multirow{2}{*}{$\begin{array}{c}\text { Bivariate } \\
\mathrm{uOR}(95 \% \mathrm{CI})\end{array}$} & \multirow[t]{2}{*}{$P$ - value } & \multirow{2}{*}{$\begin{array}{l}\text { Multivariate } \\
\mathrm{aOR}(95 \% \mathrm{CI})\end{array}$} \\
\hline & No & $\%$ & No & $\%$ & & & & \\
\hline \multicolumn{9}{|l|}{$\begin{array}{c}\text { Age bracket contribute to mens attendance } \\
\text { of } \mathrm{MCH} \text { services }\end{array}$} \\
\hline Yes & 186 & 52.8 & 35 & 17 & 0.975 & $0.9(0.6-1.7)$ & 0.408 & $0.8(0.4-1.4)$ \\
\hline No & 166 & 47.1 & 22 & 15.9 & Reference & Reference & Reference & Reference \\
\hline \multicolumn{9}{|l|}{$\begin{array}{l}\text { Do you agree that time taken in the clinic } \\
\text { (waiting time) will influence male }\end{array}$} \\
\hline Agree & 166 & 47.2 & 31 & 19 & 0.603 & $1.4(0.4-4.4)$ & 0.945 & $1.1(0.3-1.5)$ \\
\hline Strongly agree & 39 & 11.1 & 5 & 12.8 & 0.933 & $0.9(0.2-3.9)$ & 0.665 & $0.7(0.2-3.1)$ \\
\hline Disagree & 119 & 33.8 & 17 & 14.3 & 0.941 & $1.1(0.3-3.5)$ & 0.729 & $0.8(0.2-2.7)$ \\
\hline Strongly disagree & 6 & 1.7 & 1 & 17 & Reference & Reference & Reference & Reference \\
\hline \multicolumn{9}{|l|}{$\begin{array}{l}\text { Taboos that can hinder men from } \\
\text { participating in MCH services? }\end{array}$} \\
\hline Men should not be involved in womens affair & 50 & 14.2 & 10 & 20 & 0.354 & $1.4(0.7-2.8)$ & 0.346 & $1.4(0.7-3.1)$ \\
\hline $\begin{array}{l}\text { It is the duty of the woman to look after the } \\
\text { child }\end{array}$ & 35 & 9.9 & 4 & 11.4 & 0.683 & $0.8(0.3-2.3)$ & 0.704 & $0.8(0.3-2.4)$ \\
\hline $\begin{array}{l}\text { Men are the head of the house and should } \\
\text { spend time looking for food for family }\end{array}$ & 70 & 19.9 & 15 & 21.4 & 0.199 & $1.5(0.8-2.8)$ & 0.456 & $1.3(0.6-2.6)$ \\
\hline Other combined taboos & 197 & 55.9 & 28 & 14.2 & Reference & Reference & Reference & Reference \\
\hline \multicolumn{9}{|l|}{$\begin{array}{c}\text { Provider's attitude influences male } \\
\text { involvement in maternal and child services }\end{array}$} \\
\hline Yes & 223 & 63.4 & 41 & 16.4 & Reference & Reference & Reference & Reference \\
\hline No & 121 & 34.4 & 16 & 13.2 & 0.002 & $0.5(0.3-0.8)$ & 0.005 & $0.5(0.3-0.8)$ \\
\hline \multicolumn{9}{|l|}{$\begin{array}{l}\text { influence your participation in maternal } \\
\text { and child services? }\end{array}$} \\
\hline Yes & 206 & 58.5 & 35 & 17 & 0.659 & $1.1(0.7-1.9)$ & 0.955 & $1.1(0.6-1.9)$ \\
\hline No & 138 & 39.2 & 22 & 15.9 & Reference & Reference & Reference & Reference \\
\hline \multicolumn{9}{|l|}{$\begin{array}{l}\text { What clinic operation hours do you prefer } \\
\text { for you to participate in maternal and child } \\
\text { services? }\end{array}$} \\
\hline $8-12$ am & 280 & 79.5 & 46 & 16.4 & 0.064 & $6.8(0.9-51.6)$ & 0.069 & $7.4(0.9-65.9)$ \\
\hline $12-4 p m$ & 34 & 9.7 & 6 & 17.6 & Reference & Reference & Reference & Reference \\
\hline $4-8 \mathrm{pm}$ & 20 & 5.7 & 4 & 20 & 0.064 & $8.5(0.4-81.2)$ & 0.077 & $8.5(0.8-91.1)$ \\
\hline Any other & 9 & 2.6 & 1 & 11.1 & 0.018 & $7.6(1.4-40.3)$ & 0.044 & $6.7(1.1-43.5)$ \\
\hline
\end{tabular}




\section{DISCUSSION}

\section{Male involvement in MCH clinics}

To our knowledge, this is among the first studies on men's MCH clinics attendance and the role of knowledge and perception on $\mathrm{MCH}$ clinic attendance in Suba sub-county. Male attendance in maternal and child health encompasses the way men accept and indicate support to their partners' needs, choices and rights including using contraception and their own reproductive and sexual behavior to promote observance of human rights and the need to enforce equity (Kaida et al., 2010). In our context, male attendance implied accompanying the spouse to MCH clinic to seek for medical intervention and to give birth. In the current study, men's MCH clinic attendance was reported at $16.3 \%$ which was way below the average male involvement in PMTCT in Kenya with the guidelines recommending at least $\geq 30 \%$ male involvement (Odeny et al., 2013). Other studies have reported varying levels of male involvement in their spouses $\mathrm{MCH}$ clinics attendance. Higher attendance rates have been reported in southern Ethiopia, 53\% of men were involved in a PMTCT program (Tilahun \& Mohamed, 2015). In Ghana, Craymah et al., (2017) reported $35 \%, 44 \%$, and $20 \%$ men accompanied their partners to antenatal care, delivery, and postnatal care services, respectively. In Uganda Tweheyo et al., (2010) reported 48\% of men accompanied their partners during delivery. In South Africa Matseke et al., (2017) reported a 44.1\% male involvement in $\mathrm{MCH}$ clinical activities. In Ethiopia, 20.9\% of men had high involvement index in prevention of mother to child transmission of HIV/AIDS (Amano \& Musa, 2016). Lower male involvement has been reported in Uganda only $6 \%$ of male partners were found to be consistently involved in MCH services (Tweheyo et al., 2010) while in Rwanda, the well-intended initiative of male partner involvement that recommend women seeking maternal and child to be accompanied by a male partner has been interpreted as an obligation is proving to be counter productively causes delays or excludes women whereas supportive men are turned away from further health consultations (Pafs et al., 2015).

The reasons for the relatively low rates of men involvement in $\mathrm{MCH}$ clinics can be attributed to the fact that in many countries, sexual and reproductive health programs and services are centered around women, with men often lacking information that could assist them in making decisions regarding healthy behaviors and the roles they could play to promote overall family health, including accessing HIV prevention, care and treatment services (WHO, 2016). Low levels of male partner involvement in maternal and infant health and PMTCT are also partly attributed to traditional gender norms prevalent in patriarchal societies, which make involvement by men in such issues a challenge (van den Berg et al., 2015; Matseke et al., 2017).

\section{Knowledge as a factor associated with Male involvement in MCH clinics}

Although, half of participants $(54.5 \%)$ were not aware of the $\mathrm{MOH}$ effort to enhance men attendance to $\mathrm{MCH}$ clinics, awareness of this effort was associated male attendance of MCH clinic. Studies have shown that low levels on the guidelines regarding the MI in MCH affect the overall involvement. In Tanzania, August et al., (2015) the low level of knowledge on the importance of involvement in $\mathrm{MCH}$ and guideline related to $\mathrm{MCH}$ such as birth preparedness and complication readiness, affected the overall male attendance of the MCH clinic. Similarly, in Malawi, Aarnio et al., (2013) showed that men would only promptly seek care in a health facility if a woman had severe bleeding, convulsions or swelling of hands and feet. The fact that men play a 'gatekeepers' role in health care in maternal and child health is not disputed, the lack relevant knowledge in maternal and child health can be a significant barrier to their involvement (August et al., 2015). These findings call for urgent efforts train men on the importance of their involvement in matters dealing with maternal health. The number of times accompanied spouse to MCH clinic was a key factor that determined overall male involvement in MCH clinics. Men's awareness on the importance of ANC is a major driver for not only in the attendance but for support of their spouses while attending. Previous studies have shown that men are responsible for their decisions that directly impact on women and child health (Eliason et al., 2013). From the FGD and KII, the knowledge on the importance of ANC was discussed.

In FGD 3 a concerning ANC, the following was reported "I think most of men are ignorant; most of them view it that it is not them who is pregnant but the woman. So even if the woman tells him to accompany her to the clinic he doesn't see the need. Because it is the mother who is going to be tested, and it's the woman who will feel the pain and done for all those activities in the MCH. They don 't have any knowledge about being involved in the MCH". Another FGD participant was however preview to the importance of ANC and stated as follows '....... What I can add is that conceiving takes two people, so the best thing is that from the first day at ANC, it is proper for both the man and the woman to go together. Am saying that because if they go together, they can get to know their status, that if it happens that either is infected with HIV it eases the situation especially because the man can support the woman. And even if they are both infected, both of them can be helped through enrolling in care. Even through care in case of positive result, the unborn baby can be rescued from contracting the HIV infection. But in case the results are 
negative, it gives joy knowing when a woman is expecting a baby and is happy, she will give birth to a healthy child"

Time taken to accompany spouse for the $\mathrm{MCH}$ clinic was an independent crucial factor determining their involvement. Studies have shown men as the family bread winner and the time spent at the MCH clinic tended to be in contrast with the men's timing for getting source of income (Odeny et al., 2013). In our study knowledge and the use of family planning methods was associated with men's MCH clinic attendance. Studies have shown that the lack of knowledge by men related to family planning services including the desire to have more children and lack of knowledge about contraceptive use, determines men's attendance of MCH clinics (August et al., 2015). The place of last child delivery and knowledgeable about the methods used to reduce HIV mother to child transmission were also important factors associated with men's attendance of the MCH clinics. This finding supported by Tweheyo et al., (2010) who showed that once men felt they knew more about antenatal care, they felt more driven to accompany their spouses.

\section{Perception as a factor for male involvement in MCH clinics}

Provider's attitude was an independent perception factor associated with men's attendance of the MCH clinics. Studies have highlighted the importance of health personnel and hospital environment as key determinate to men involvement in MCH services. Health system's policy (that advocates for male involvement) contrast sharply with the reality. The unwelcoming hospital environment is characterized by lack of privacy, absence of facilities in which men would be comfortable, apparent neglect by healthcare providers, lack of communication and near-total exclusion of men "who are willing to be involved" from healthcare issues of their spouses at this critical time (August et al., 2015).

Time preferences of clinic operation hour for MCH services were independently associated with men's attendance of the $\mathrm{MCH}$ clinics. Generally, clinic waiting time has been reported as a major hindrance to male involvement in $\mathrm{MCH}$ clinic.

This was reinforced in by one of the FGDs in which one participant had this to say; '......... most of the mothers that come here, their husbands are fishermen, so they go to work at night and come back around 10. am, and 10.am the mother is already here at the clinic unaccompanied by their spouses......' (FGD3 for men).

Our study is consistent with the findings of Adeleye \& Chiwuzie, (2007) in Nigeria which showed that 74.6\% men were not willing to participate in a PMTCT programs by accompanying their wives to antenatal clinics because they are often too busy. Further, confirmed by Theuring et al., (2009) who reported long waiting time as a major deterrent to $\mathrm{MI}$ in $\mathrm{MCH}$ clinics. No wonder majority of men in this study preferred to accompany their spouses to $\mathrm{MCH}$ clinic between 4-8 pm than between $8 \mathrm{am}-12 \mathrm{pm}$, a time in the morning hours corresponding to time when men were engaged in other activities that would bring income to the family for survival.

One of the major strengths of this study is the ability to contribute to wealth of knowledge by showing that men involvement in $\mathrm{MCH}$ clinics though low can be improved by addressing the associated factors not only in this region but in Kenya as a whole. The study also showed the potential association between awareness of health ministry's guidelines, history of male involvement in $\mathrm{MCH}$ clinics, time taken to $\mathrm{MCH}$ clinic, preferential time for clinic operation, use of family planning methods, place of last child delivery, provider's attitude and hour and awareness about the methods used to reduce HIV mother to child transmission and the associated with men's attendance of the $\mathrm{MCH}$ clinics. However, some of the limitation to our assessment needs to be pointed out: Firstly, cross-sectional nature of our study only allowed us to describe associations between men MI and MCH clinics, not a causal conclusion. Such outcomes can be confirmed in a longitudinal study. Secondly, report shows that about $16.3 \%$ men accompanied their spouses to MCH clinic, we may not have captured the true MI in MCH clinics in this study. These limitations notwithstanding, our findings indicate men are involved in $\mathrm{MCH}$ services and enhance dissemination and awareness creation on the importance of $\mathrm{MI}$ in $\mathrm{MCH}$ services could improve male involvement.

\section{Authors' contributions}

Noel Otieno Odhiambo (NOO), Harrison Atieli (HA) and Louisa Ndunyu (LN) conceived the study. NOO collected and analyzed the data and prepared the draft manuscript. LN provided guidance and mentorship during the implementation of the study. All authors reviewed and approved the final manuscript.

\section{Competing interests}

The authors declare that they have no competing interest. 


\section{Acknowledgments}

This work was carried out Suba sub County in Western Kenya. We thank the study participants for their invaluable support by consenting to take part in this study. This work was part of Master of public (Epidemiology and Population Health) NOO

\section{REFERENCE}

1. Aarnio, P., Chipeta, E., \& Kulmala, T. (2013). Men's perceptions of delivery care in rural Malawi: exploring community level barriers to improving maternal health. Health Care Women Int, 34(6), 419-439.

2. Adeleye, O. A., \& Chiwuzie, J. (2007). "He does his own and walks away" perceptions about male attitudes and practices regarding safe motherhood in Ekiadolor, Southern Nigeria. Afr J Reprod Health, 11(1), 76-89.

3. Alio, A. P., Kornosky, J. L., Mbah, A. K., Marty, P. J., \& Salihu, H. M. (2010). The impact of paternal involvement on feto-infant morbidity among Whites, Blacks and Hispanics. Matern Child Health J, 14(5), 735-741.

4. Amano, A., \& Musa, A. (2016). Male involvement in PMTCT and associated factors among men whom their wives had ANC visit 12 months prior to the study in Gondar town, North west Ethiopia, December, 2014. Pan Afr Med J, 24, 239. doi:10.11604/pamj.2016.24.239.8460

5. Ampt, F., Mon, M. M., Than, K. K., Khin, M. M., Agius, P. A., Morgan, C., Luchters, S. (2015). Correlates of male involvement in maternal and newborn health: a cross-sectional study of men in a peri-urban region of Myanmar. BMC Pregnancy Childbirth, 15, 122.

6. August, F., Pembe, A. B., Mpembeni, R., Axemo, P., \& Darj, E. (2015). Men's Knowledge of Obstetric Danger Signs, Birth Preparedness and Complication Readiness in Rural Tanzania. PLoS One, 10(5), e0125978.

7. Bernard, H.R. (1994). "Research methods in anthropology": Qualitative and quantitative approaches 2nded. London, Sage Publications, 1994

8. Brubaker, K., Nelson, B. D., McPherson, H., Ahn, R., Oguttu, M., \& Burke, T. F. (2016). Qualitative study of the role of men in maternal health in resource-limited communities in western Kenya. Int J Gynaecol Obstet, 135(3), 245-249.

9. Comrie-Thomson, L., Tokhi, M., Ampt, F., Portela, A., Chersich, M., Khanna, R., \& Luchters, S. (2015). Challenging gender inequity through male involvement in maternal and newborn health: critical assessment of an emerging evidence base. Cult Health Sex, 17 Suppl 2, S177-189.

10. Craymah, J. P., Oppong, R. K., \& Tuoyire, D. A. (2017). Male Involvement in Maternal Health Care at Anomabo, Central Region, Ghana. Int J Reprod Med, 2017, 2929013.

11. DeCock. (2012). Prevention of Mother to Child HIV Transmission in Resource Poor Countries. Journal of the American Medical Association, 2002, 322:152-169.

12. Ditekemena, J., Koole, O., Engmann, C., Matendo, R., Tshefu, A., Ryder, R., \& Colebunders, R. (2012). Determinants of male involvement in maternal and child health services in sub-Saharan Africa: a review. Reprod Health, 9, 32.

13. Elias, M., Mmbaga, E. J., Mohamed, A. A., \& Kishimba, R. S. (2017). Male partner involvement in the prevention of mother to child transmission of HIV infection in Mwanza Region, Tanzania. Pan Afr Med J, 27, 90. doi:10.11604/pamj.2017.27.90.8901

14. Eliason, S., Baiden, F., Quansah-Asare, G., Graham-Hayfron, Y., Bonsu, D., Phillips, J., \& Awusabo-Asare, K. (2013). Factors influencing the intention of women in rural Ghana to adopt postpartum family planning. Reprod Health, 10, 34. doi:10.1186/1742-4755-10-34

15. Green, J., \& Thorogood, N. (2010): Qualitative Methods for Health Research, (2 edn.) Lodon: Sage Publication, 2010.

16. Gungor, I., \& Beji, N. K. (2007). Effects of fathers' attendance to labor and delivery on the experience of childbirth in Turkey. West J Nurs Res, 29(2), 213-231. doi:10.1177/0193945906292538

17. Kaida, K., Laher, F., Strathdee, S. A., Money, D., Janssen, P. A., Hogg, R. S., \& Gray, G. (2010). Contraceptive use and method preference among women in Soweto, South Africa: the influence of expanding access to HIV care and treatment services. PLoS One, 5(11), e13868.

18. KNBS. (2014). Kenya Demographic and Health Survey

19. Kululanga, L. I., Sundby, J., Malata, A., \& Chirwa, E. (2011). Striving to promote male involvement in maternal health care in rural and urban settings in Malawi - a qualitative study. Reprod Health, 8, 36. doi:10.1186/1742-4755-8-36

20. Kwambai, T. K., Dellicour, S., Desai, M., Ameh, C. A., Person, B., Achieng, F., . . Ter Kuile, F. O. (2013). Perspectives of men on antenatal and delivery care service utilisation in rural western Kenya: a qualitative study. BMC Pregnancy Childbirth, 13, 134. doi:10.1186/1471-2393-13-134 
21. Lemeshow, S., Hosmer, D.K., Klar, J., \& Lwanga, S.K., (1990). "World health Organization. Adequacy of samples size in health studies. A vailable www.tbrieder.org/publications/books_english/lemeshow_samplesize.pdf. Accessed 3rd Nov, 2017.

22. Matseke, M. G., Ruiter, R. A. C., Rodriguez, V. J., Peltzer, K., Setswe, G., \& Sifunda, S. (2017). Factors Associated with Male Partner Involvement in Programs for the Prevention of Mother-to-Child Transmission of HIV in Rural South Africa. Int J Environ Res Public Health, 14(11). doi:10.3390/ijerph14111333

23. NACC. (2016). National AIDS Control Council Report.

24. Nanjala, M., \& Wamalwa, D. (2012). Determinants of male partner involvement in promoting deliveries by skilled attendants in Busia, Kenya. Glob J Health Sci, 4(2), 60-67.

25. Nkuoh, G. N., Meyer, D. J., Tih, P. M., \& Nkfusai, J. (2010). Barriers to men's participation in antenatal and prevention of mother-to-child HIV transmission care in Cameroon, Africa. J Midwifery Womens Health, 55(4), 363-369.

26. Nwakwuo, G. C., \& Oshonwoh, F. E. (2013). Assessment of the level of male involvement in safe motherhood in southern Nigeria. J Community Health, 38(2), 349-356.

27. Odeny, T. A., Penner, J., Lewis-Kulzer, J., Leslie, H. H., Shade, S. B., Adero, W., . . Bukusi, E. A. (2013). Integration of HIV Care with Primary Health Care Services: Effect on Patient Satisfaction and Stigma in Rural Kenya. AIDS Res Treat, 2013, 485715. doi:10.1155/2013/485715

28. Pafs, J., Musafili, A., Binder-Finnema, P., Klingberg-Allvin, M., Rulisa, S., \& Essen, B. (2015). 'They would never receive you without a husband': Paradoxical barriers to antenatal care scale-up in Rwanda. Midwifery, 31(12), 1149-1156.

29. Theuring, S., Mbezi, P., Luvanda, H., Jordan-Harder, B., Kunz, A., \& Harms, G. (2009). Male involvement in PMTCT services in Mbeya Region, Tanzania. AIDS Behav, 13 Suppl 1, 92-102.

30. Tilahun, M., \& Mohamed, S. (2015). Male Partners' Involvement in the Prevention of Mother-to-Child Transmission of HIV and Associated Factors in Arba Minch Town and Arba Minch Zuria Woreda, Southern Ethiopia. Biomed Res Int, 2015, 763876.

31. Tweheyo, R., Konde-Lule, J., Tumwesigye, N. M., \& Sekandi, J. N. (2010). Male partner attendance of skilled antenatal care in peri-urban Gulu district, Northern Uganda. BMC Pregnancy Childbirth, 10, 53.

32. UNAIDS. (2015). Annual report. (http://www.unaids.org/en/aboutunaids/contactunaids/fraud_alert).

33. van den Berg, W., Brittain, K., Mercer, G., Peacock, D., Stinson, K., Janson, H., \& Dubula, V. (2015). Improving men's participation in preventing mother-to-child transmission of HIV as a maternal, neonatal, and child health priority in South Africa. PLoS Med, 12(4), e1001811.

34. WHO. (2016). "Maternal MortalityEstimates developed by WHO, UNICEF, UNFPA and the World Bank. World Health Organization: Geneva; 2007.".

35. Yargawa, J., \& Leonardi-Bee, J. (2015). Male involvement and maternal health outcomes: systematic review and meta-analysis. J Epidemiol Community Health, 69(6), 604-612. 